Article

\title{
Novel Photocatalytic Nanocomposite Made of Polymeric Carbon Nitride and Metal Oxide Nanoparticles
}

\author{
Iwona Koltsov ${ }^{1, *}$, Jacek Wojnarowicz ${ }^{1}{ }^{(\mathbb{D}}$, Piotr Nyga $^{2}{ }^{\mathbb{D}}$, Julita Smalc-Koziorowska ${ }^{1}$, \\ Svitlana Stelmakh ${ }^{1}$, Aleksandra Babyszko ${ }^{3}$, Antoni W. Morawski ${ }^{3}{ }^{1-}$ and Witold Lojkowski ${ }^{1}$ \\ 1 Institute of High Pressure Physics, Polish Academy of Sciences, Sokolowska 29/37, 01-142 Warsaw, Poland; \\ j.wojnarowicz@labnano.pl (J.W.); julita.smalc.koziorowska@unipress.waw.pl (J.S.-K.); \\ svetlana.stelmakh@unipress.waw.pl (S.S.); w.lojkowski@labnano.pl (W.L.) \\ 2 Military University of Technology, Institute of Optoelectronics, Urbanowicza 2, 00-908 Warsaw, Poland; \\ piotr.nyga@wat.edu.pl \\ 3 West Pomeranian University of Technology Szczecin, Pułaskiego 10, 70-322 Szczecin, Poland; \\ ba08645@zut.edu.pl (A.B.); amor@zut.edu.pl (A.W.M.) \\ * Correspondence: iwona.koltsov@unipress.waw.pl; Tel.: +48-22-888-0036
}

Academic Editor: Dimitrios Bikiaris

Received: 25 January 2019; Accepted: 26 February 2019; Published: 1 March 2019

\begin{abstract}
Semiconducting polymers are promising materials for photocatalysis, batteries, fuel applications, etc. One of the most useful photocatalysts is polymeric carbon nitride (PCN), which is usually produced during melamine condensation. In this work, a novel method of obtaining a PCN nanocomposite, in which PCN forms an amorphous layer coating on oxide nanoparticles, is presented. Microwave hydrothermal synthesis (MHS) was used to synthesize a homogeneous mixture of nanoparticles consisting of $80 \mathrm{wt} . \% \mathrm{AlOOH}$ and $20 \mathrm{wt} . \%$ of $\mathrm{ZrO}_{2}$. The nanopowders were mechanically milled with melamine, and the mixture was annealed in the temperature range of $400-600{ }^{\circ} \mathrm{C}$ with rapid heating and cooling. The above procedure lowers PCN formation to $400{ }^{\circ} \mathrm{C}$. The following nanocomposite properties were investigated: band gap, specific surface area, particle size, morphology, phase composition, chemical composition, and photocatalytic activity. The specific surface of the PCN nanocomposite was as high as $70 \mathrm{~m}^{2} / \mathrm{g}$, and the optical band gap was $3 \mathrm{eV}$. High photocatalytic activity in phenol degradation was observed. The proposed simple method, as well as the low-cost preparation procedure, permits the exploitation of PCN as a polymer semiconductor photocatalytic material.
\end{abstract}

Keywords: microwave hydrothermal synthesis; $\mathrm{AlOOH}-\mathrm{ZrO}_{2}$; nanocomposites; polymeric carbon nitride (PCN); band gap; photocatalysis; $\gamma-\mathrm{Al}_{2} \mathrm{O}_{3}-\mathrm{ZrO}_{2}$ nanopowders

\section{Introduction}

Photocatalysis is based on the photoabsorption by a semiconducting material at its surface. Photon absorption leads to the generation of electron-hole pairs, and the electron should reach the surface without hole-electron recombination. Therefore, considerable efforts have been made to enhance photocatalytic performance by effective charge separation. The major problems associated with a single organic component photocatalyst are as follows: (I) low specific surface area (SSA $\mathrm{BET}_{\mathrm{BET}}$ ) of the photocatalyst materials, which limits the interactions of the organic molecules with the photocatalyst surface, and (II) poor stability and reusability [1]. In recent years, binary or ternary photocatalysts have attracted considerable attention owing to their favorable advanced oxidation processes under stimulated light $[2,3]$. Over the last few decades, numerous approaches have been developed to enhance the photocatalytic efficiency of a photocatalyst, including doping with various chemical 
elements ( $\mathrm{Cr}, \mathrm{Fe}, \mathrm{B}, \mathrm{S})$ [4-7], incorporating co-catalysts [8], including oxides [9], or the coupling of two or more semiconductors. Some of these have shown promising photocatalytic activities for the degradation of toxic pollutants under visible light irradiation because of their structural features and suitable band gaps in the range of $1.7-3 \mathrm{eV}$. However, the challenge is to find a semiconductor photocatalyst that is synthesized in an energy-efficient way, does not use critical raw materials, and does not require complicated post-synthesis modifications to tune the band gap.

Recently, the attention of scientists has been focused on manufacturing composites and heterojunctions involving $\mathrm{C} / \mathrm{N} / \mathrm{H}$-containing solids, especially on synthesizing a material called graphitic carbon nitride $\left(\mathrm{g}-\mathrm{C}_{3} \mathrm{~N}_{4}\right)$ [10], polymeric carbon nitride (PCN), or melon [11]. This compound is a product of melamine thermal condensation, possesses an optical band gap of $2.7 \mathrm{eV}$, and has great chemical stability [10]. The polymeric organic semiconductor PCN was reported mainly as a favorable photocatalyst in water splitting for hydrogen production [10]. Due to its properties, polymeric carbon nitride has also been used in the fields of photocatalysis, electrochemistry, and photo-electrochemistry [10,11].

Despite various advantages, PCN is characterized by low photocatalytic activity, which is caused by the rapid recombination of photo-generated electron-hole pairs [12-15], and a low specific surface area $\left(\mathrm{SSA}_{\mathrm{BET}}\right)$. Thus, there is a need to improve its surface by various modifications and structural adjustments [16]. The introduction of a metal oxide (e.g., $\mathrm{ZnO}, \mathrm{TiO}_{2}, \mathrm{Al}_{2} \mathrm{O}_{3}$, etc.) to $\mathrm{PCN}$ in order to form a heterostructured composite was found to be an effective method to enhance the long-term photostability and thermal stability [17]. However, the specific surface area of these composites is not high enough. PCN displays a SSA $\mathrm{BET}$ of approximately, or even below, $10 \mathrm{~m}^{2} / \mathrm{g}$ [17]. To date, many complicated preparation methods have been developed to obtain PCN-based materials with larger $\mathrm{SSA}_{\mathrm{BET}}$. In principle, these methods can be classified into two categories. One category involves changing the morphology (e.g., porous nanostructure, hollow spheres, etc.) of PCN by template-assisted methods [17-22]. Another category is top-down chemical or thermal exfoliation of bulk PCN [17]. However, the abovementioned methods need additional post-treatment processes. Obviously, a simple, direct, and template-free strategy to synthesize PCN-based materials with large $\mathrm{SSA}_{\mathrm{BET}}$ is desired.

The aim of our work was to utilize $\mathrm{AlOOH}$ (i.e., boehmite, aluminum oxyhydroxide) and $\mathrm{ZrO}_{2}$ nanoparticles in microwave hydrothermal synthesis as components of a PCN nanocomposite. The role of microwave hydrothermal synthesis in the obtaining of $\mathrm{AlOOH}-\mathrm{ZrO}_{2}$ nanopowders during co-synthesis is described in our previous works [23-25]. Briefly, the process ensures a narrow size distribution, a high degree of crystallinity, and uniform intermixing of the two nanopowders in nanoscale $[23,24,26-29]$. The justification for the use of homogeneous $\mathrm{AlOOH}-\mathrm{ZrO}_{2}$ nanopowders as a substrate for the deposition of $\mathrm{PCN}$ is to provide increased specific surface area ( $\mathrm{SSA}_{\mathrm{BET}}$ ) and provide suitable thermal and mechanical stability. To the best of our knowledge, the role of homogeneous nanopowders of $\mathrm{AlOOH}-\mathrm{ZrO}_{2}$ in $\mathrm{PCN}$ nanocomposite formation is investigated here for the first time. All the ingredients of the nanocomposite, $\mathrm{AlOOH}, \mathrm{ZrO}_{2}$, and $\mathrm{PCN}$ are earth-abundant, which makes our PCN nanocomposite an ideal, inexpensive photocatalyst candidate.

\section{Results}

\section{Nanocomposite Characterization}

The starting homogeneous nanopowders of $\mathrm{AlOOH}-\mathrm{ZrO}_{2}$ used in this work consisted of $80 \mathrm{wt} . \%$ of $\mathrm{AlOOH}$ and $20 \mathrm{wt} . \%$ of $\mathrm{ZrO}_{2}$ [23-25]. In order to mill it with melamine, $80 \mathrm{wt} . \%$ of the nanopowders and $20 \mathrm{wt} . \%$ of melamine were used. The mixture was annealed at $400,450,500$, and $600{ }^{\circ} \mathrm{C}$. The synthesized nanocomposites were cooled with reference to the annealing temperature for better clarity.

Figure 1a shows the FTIR spectra for the nanocomposites manufactured in the temperature range of $400-600{ }^{\circ} \mathrm{C}$. In this experiment, polymeric carbon nitride was identified only in the nanocomposite 
prepared at $400{ }^{\circ} \mathrm{C}$. It has been reported that the absorption band in the $1420-1620 \mathrm{~cm}^{-1} \mathrm{region}^{-}$ is assigned to $\mathrm{CN}$ stretching and $-\mathrm{NH}_{2}$ bending vibrations in melamine [16]. The broad peak at $3100-3400 \mathrm{~cm}^{-1}$ can be attributed to the stretching vibration of $\mathrm{N}-\mathrm{H}$ and $\mathrm{O}-\mathrm{H}$. The other peaks at 1257 and $1326 \mathrm{~cm}^{-1}$ are present due to the stretching vibration of aromatic $\mathrm{C}-\mathrm{N}$ heterocycles consisting of trigonal $\mathrm{N}-\mathrm{C}_{3}$ and $\mathrm{C}-\mathrm{NH}-\mathrm{C}$ bridging units [16], representing the formation of $\mathrm{C}-\mathrm{N}-\mathrm{C}$ bonds. The main indication of melon in a sample is the presence of a band around $800 \mathrm{~cm}^{-1}$, which belongs to triazine ring vibration in PCN [16]. It can be seen that the higher the annealing temperature of the nanocomposites, the weaker the intensity of the $\mathrm{C}-\mathrm{N}$ bands.

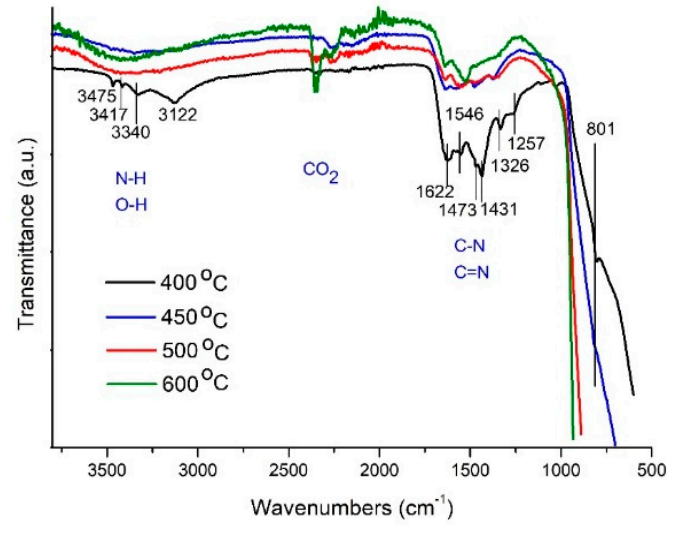

(a)

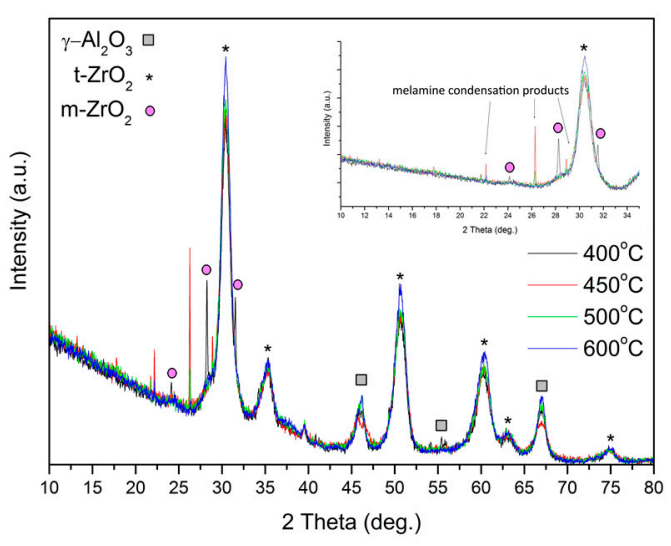

(b)

Figure 1. (a) FTIR spectra and (b) XRD spectra of the nanocomposites prepared in the temperature range $400-600{ }^{\circ} \mathrm{C}$.

Figure $1 \mathrm{~b}$ presents the $\mathrm{X}$-ray powder diffraction (XRD) spectra of the nanocomposites annealed in the temperature range of $400-600^{\circ} \mathrm{C}$. Interestingly, XRD analysis does not show the presence of the $\mathrm{AlOOH}$ phase even in the nanocomposite annealed at $400{ }^{\circ} \mathrm{C}$. The phase transition of $\mathrm{AlOOH}$ to $\gamma-\mathrm{Al}_{2} \mathrm{O}_{3}$ already took place [23]. Besides the $\gamma-\mathrm{Al}_{2} \mathrm{O}_{3}$ phase, all the samples contained $\mathrm{ZrO} \mathrm{O}_{2}$. In addition, the nanocomposite annealed at $450{ }^{\circ} \mathrm{C}$ contained traces of melamine condensation procucts. The lack of the PCN phase in the nanocomposite annealed at $400{ }^{\circ} \mathrm{C}$ may indicate an amorphous phase of this compound.

For the TEM examination, we chose only the composition that contains PCN (Figure 1a). Figure 2 shows the TEM images of the nanocomposite obtained at $400{ }^{\circ} \mathrm{C}$. It is possible to distinguish three types of morphology: tetrahedral 30-50 nm flakes, which can be assigned to $\gamma-\mathrm{Al}_{2} \mathrm{O}_{3}$; spherical 3-5 nm $\mathrm{ZrO}_{2}$ particles; and 5-10 nm amorphous layers, which can be assigned to PCN (Figure 2b,d).

Table 1 presents the results of $\mathrm{SSA}_{\mathrm{BET}}$, helium density, and the average particle size of the nanocomposites obtained at various temperatures. There is a visible difference between SSA BET $_{\text {for }}$ the nanocomposite annealed at $400{ }^{\circ} \mathrm{C}$ and for the nanocomposites obtained at higher temperatures.

Table 1. Specific surface area, helium density, particle size, and pores dimensions of the investigated materials. The $\mathrm{SSA}_{\mathrm{BET}}$ represents specific surface area, and BJH describes BarrettJoyner-Halenda method.

\begin{tabular}{cccccc}
\hline Sample Name & $\begin{array}{c}\text { SSA } \\
\text { Multipoint } \\
\left(\mathbf{m}^{2} / \mathbf{g}\right)\end{array}$ & $\begin{array}{c}\text { Density } \\
\left(\mathbf{g} / \mathbf{c m}^{3}\right)\end{array}$ & $\begin{array}{c}\text { Average Particle } \\
\text { Size Calculated } \\
\text { from SSA }\end{array}$ & $\begin{array}{c}\text { BJH Adsor } \mathbf{( n m}) \\
\text { Average Pore }\end{array}$ & $\begin{array}{c}\text { Total Pore } \\
\text { Volume } \\
\text { Diameter }(\mathbf{n m})\end{array}$ \\
$\mathbf{( \mathbf { c m } ^ { 3 } / \mathbf { g } )}$
\end{tabular}


The reference sample $\gamma-\mathrm{Al}_{2} \mathrm{O}_{3}-\mathrm{ZrO}_{2}$ nanopowder annealed at $400{ }^{\circ} \mathrm{C}$ is characterized by a SSA $\mathrm{BET}$ of $108 \mathrm{~m}^{2} / \mathrm{g}$. The presence of a thin, nanometric PCN layer on the nanoparticle surface slightly reduces $\mathrm{SSA}_{\mathrm{BET}}$ (nanocomposite $400^{\circ} \mathrm{C}$, Table 1). On the other hand, the SSA BET value of above $100 \mathrm{~m}^{2} / \mathrm{g}$ for the nanocomposites annealed at 450 and $500{ }^{\circ} \mathrm{C}$ could be the result of the crystallization of some of the melamine condensation products, which decompose at higher temperatures. It is worth noting that the pure $\gamma-\mathrm{Al}_{2} \mathrm{O}_{3}-\mathrm{ZrO}_{2}$ obtained after annealing at $400{ }^{\circ} \mathrm{C}$ (reference for $\mathrm{PCN}$ nanocomposite $400{ }^{\circ} \mathrm{C}$ ) had an evident influence on the SSA $\mathrm{BET}$ of the PCN nanocomposite (Table 1). The deposition of the PCN layer on $\mathrm{Al}_{2} \mathrm{O}_{3}-\mathrm{ZrO}_{2}$ reduced slightly the SSABET from 108 to $\sim 80 \mathrm{~m}^{2} / \mathrm{g}$. This value of $\mathrm{SSA}_{\mathrm{BET}}$ for the PCN nanocomposite is relatively high, because pure PCN is characterized by a SSA $\mathrm{BET}$ of $\sim 10 \mathrm{~m}^{2} / \mathrm{g}$ [26].

Interestingly, the density values of the nanocomposites annealed at 400,500 , and $600{ }^{\circ} \mathrm{C}$ are nearly the same. Only one sample (the nanocomposite annealed at $450{ }^{\circ} \mathrm{C}$ ) has a slightly lower density (Table 1). In addition, all the prepared nanocomposites showed smaller densities than the reference sample with a density of $3.75 \mathrm{~g} / \mathrm{cm}^{3}\left(\mathrm{Al}_{2} \mathrm{O}_{3}-\mathrm{ZrO}_{2}\right.$ annealed at $\left.400{ }^{\circ} \mathrm{C}\right)$. This fact could be explained by the reduction of $\mathrm{Zr}^{4+}$ and $\mathrm{Al}^{3+}$ ions in the presence of melamine ok its decomposition products, obtaining metallic precipitations not visible during XRD examination. Thus, these ions could lead to the increased density of the PCN nanocomposites in comparison with the reference sample.

The relationship between $\mathrm{SSA}_{\mathrm{BET}}$ and the density values for the homogenous nanomaterials was observed in our prior research $[27,28]$ : the higher the SSA $\mathrm{BET}$, the smaller the density. Our PCN nanocomposites do not show the abovementioned trend (Table 1). In this case, the SSA BET $_{\text {differs }}$ while the density remains approximately constant. We attribute that lack of significant change of the density to the applied annealing temperature, melamine condensation, and its interconversion processes. It means, for example, that for nanocomposites prepared at $450{ }^{\circ} \mathrm{C}$, the nanoparticles and pores of $\mathrm{Al}_{2} \mathrm{O}_{3}-\mathrm{ZrO}_{2}$ are covered by a PCN layer (closed pores), which causes lower density (helium pycnometry). At higher temperatures, the PCN undergoes further interconversion and decomposition, which increases the SSA $\mathrm{BET}$ while the density remains at the same value.

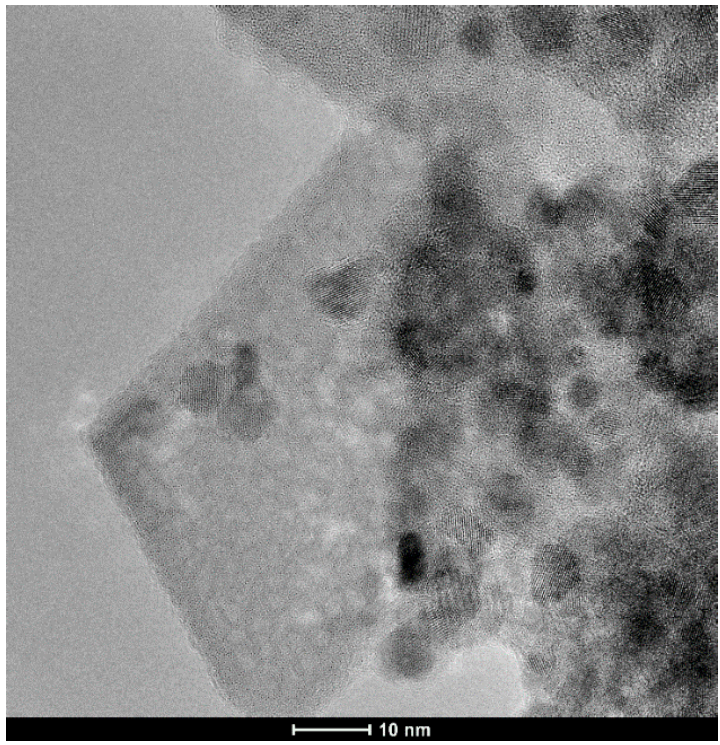

(a)

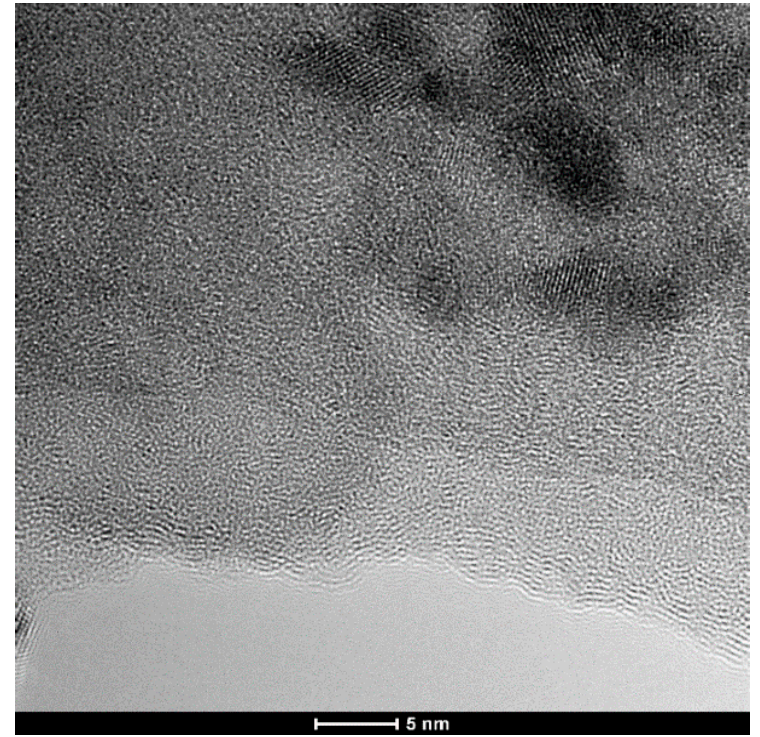

(b)

Figure 2. Cont. 


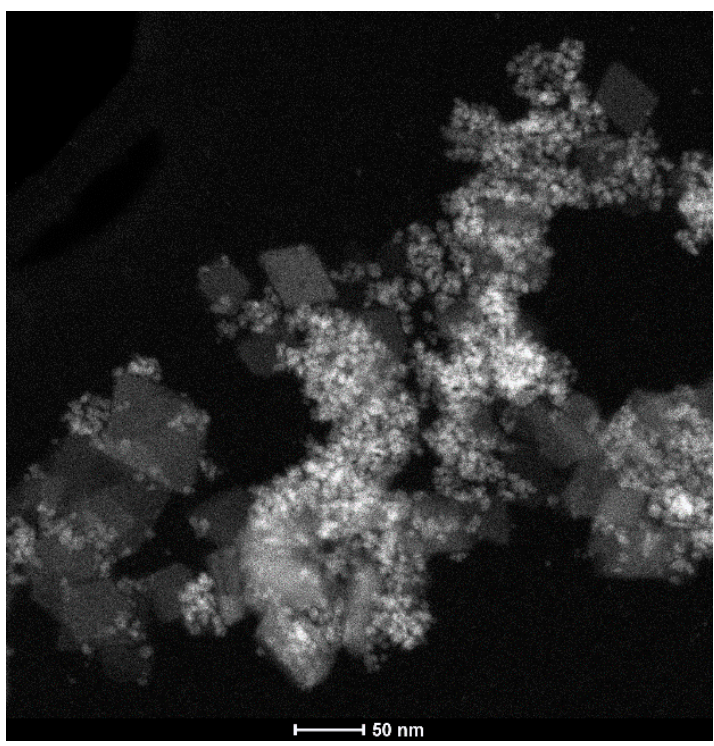

(c)

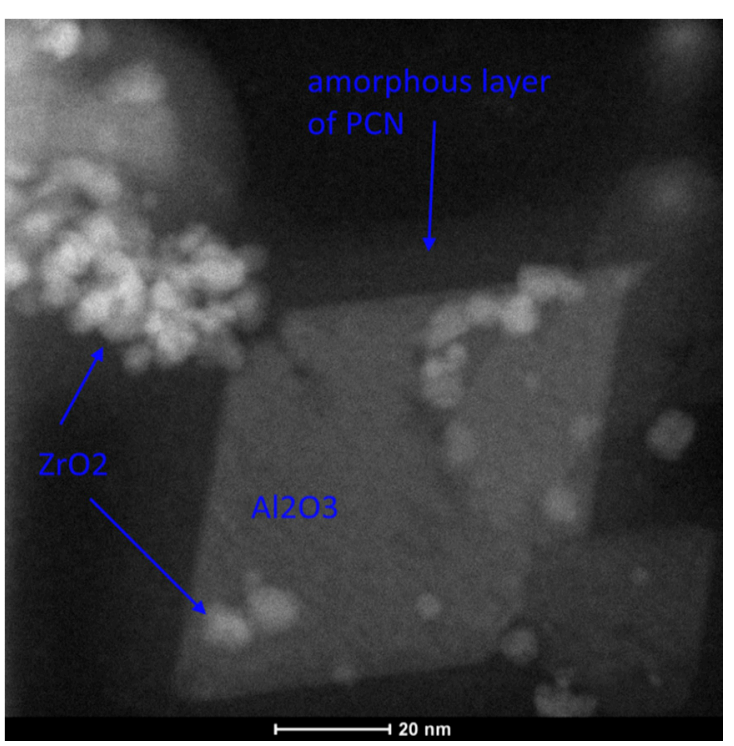

(d)

Figure 2. (a,b) TEM images of the nanocomposite obtained at $400{ }^{\circ} \mathrm{C} ;(\mathbf{c}, \mathbf{d})$ STEM images of the nanocomposite obtained at $400{ }^{\circ} \mathrm{C}$.

Table 1 also shows the average pore diameter and total pore volume for the investigated nanocomposites. There is no influence of porosity on the photocatalytic properties of the nanocomposites. Nanocomposite $400{ }^{\circ} \mathrm{C}$ has the smallest $\mathrm{SSA}_{\mathrm{BET}}$ and porosity and shows the largest photocatalytic effect. He et al. [29], who investigated polyoxometalate (POMs)-functionalized g- $\mathrm{C}_{3} \mathrm{~N}_{4}$, showed that, compared with $\mathrm{C}_{3} \mathrm{~N}_{4}$, POMs-modified samples demonstrated slightly better efficiencies in photodegradation of phenol and Methylene blue (MB). It was suggested that the increased specific surface area, porous volume, and efficient charge transfer can influence photocatalysis [26].

In comparison to $\mathrm{He}$ et al. [26], our materials are characterized by higher specific surface areas and bigger pore volumes. Thus, we think that the active PCN layer on the surface of $\mathrm{Al}_{2} \mathrm{O}_{3}-\mathrm{ZrO}_{2}$ prepared at $400{ }^{\circ} \mathrm{C}$ has a greater effect on photocatalytic performance in our case than $\mathrm{SSA}_{\mathrm{BET}}$ and the material's pore volume.

Figure 3a shows the total reflectance of the nanocomposites prepared in the temperature range of $400-500{ }^{\circ} \mathrm{C}$. As-synthesized (AS) $\mathrm{AlOOH}-\mathrm{ZrO}_{2}$ homogenous nanopowders after annealing at $600{ }^{\circ} \mathrm{C}$, where $\mathrm{AlOOH}$ transformed completely into $\gamma-\mathrm{Al}_{2} \mathrm{O}_{3}$, were added as a reference.

The reflectance of all the samples in the longer wavelength area of the spectrum is relatively high. In order to calculate the material band gap, we used the procedure described in [30,31]. Briefly, the reflectance was converted into a Kubelka-Munk function using Equation (1) [32,33]:

$$
F(R)=\frac{(1-R)^{2}}{2 R}
$$

where $F(R)$ is the Kubelka-Munk function and $R$ is the sample reflectance.

Information about the band gap (Eg) can be obtained using the equation proposed by Tauc, Davis, and Mott, i.e., Equation (2) [34,35]:

$$
\alpha h v=A(h v-E g)^{1 / n}
$$

where $\alpha$ is the absorption of the material, $\mathrm{h}$ is the Planck constant, $v$ the frequency of light, and Eg is the band gap. The exponent $1 / \mathrm{n}$ depends on the type of transition in the material, and for the cases of all the samples, we assumed a direct transition; thus, $n=2$. Because $F(R)$ is proportional to $\alpha$ [36], one can determine the band gap from the following formula:

$$
(F(R) h v)^{2}=A(h v-E g)
$$


The band gap can be determined from a plot of $(F(R) h v)^{2}$ against $h v$ by extrapolating the $F(R)$ value to zero (Figure $3 \mathrm{~b}$ ). Table 2 shows the calculated band gap values for the investigated materials.

Photocatalytic properties of the nanocomposites prepared at 400,450 , and $500{ }^{\circ} \mathrm{C}$ are presented in Figures 4 and 5. In addition, the photocatalytic tests were also performed for a reference sample: $\mathrm{AlOOH}-\mathrm{ZrO}_{2}$ nanopowders annealed at $400{ }^{\circ} \mathrm{C}$ for $5 \mathrm{~h}$ (after annealing, the nanopowders consisted of $\gamma-\mathrm{Al}_{2} \mathrm{O}_{3}$ and $\mathrm{ZrO}_{2}$ ). Figures 4 and 5 show phenol and Orange II adsorption and decomposition in the presence of the mentioned nanocomposites, respectively.

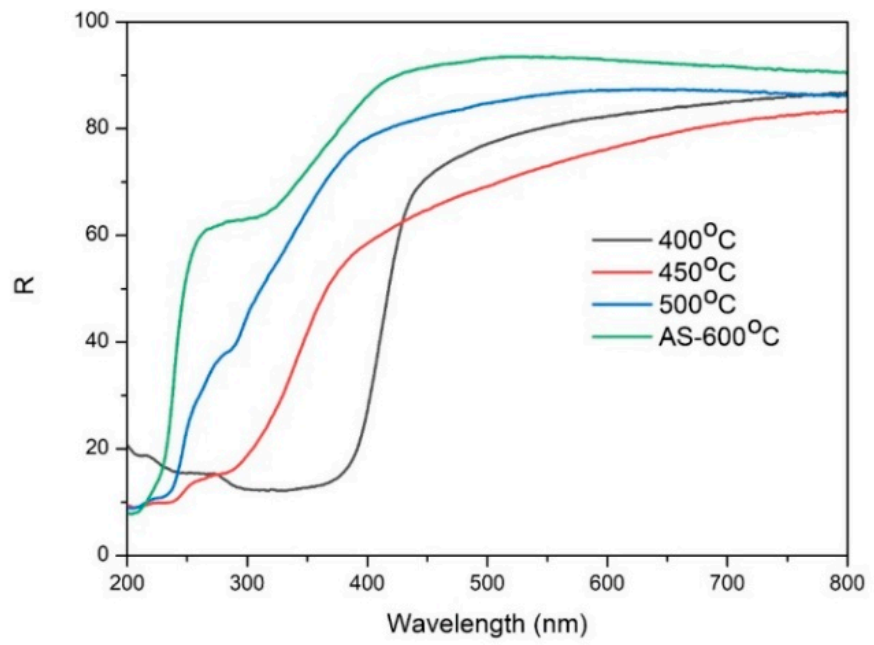

(a)
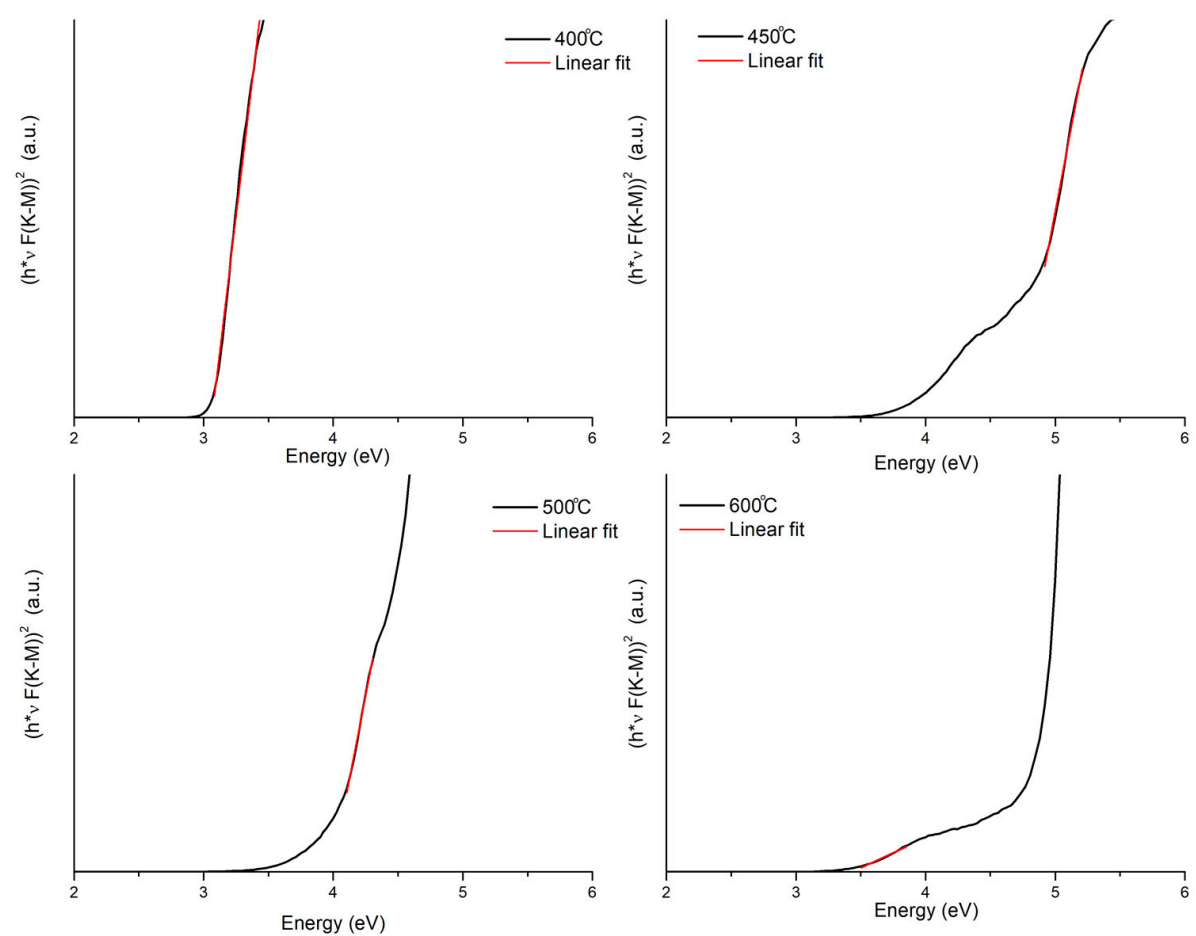

(b)

Figure 3. (a) Total reflectance of the nanocomposites prepared in the $400-500{ }^{\circ} \mathrm{C}$ temperature range. In addition, the $\mathrm{AlOOH}-\mathrm{ZrO}_{2}$ nanopowders annealed at $600{ }^{\circ} \mathrm{C}$ were added as a reference $\left(\mathrm{AS} 600{ }^{\circ} \mathrm{C}\right.$, green line). (b) Reflectance UV-Vis spectra of Kubelka-Munk (K-M) functions vs energy (eV) for the investigated materials. 
Table 2. Band gap values calculated for the investigated nanocomposites.

\begin{tabular}{cc}
\hline Sample Name & Band Gap (eV) \\
\hline Nanocomposite $400^{\circ} \mathrm{C}$ & 3.0 \\
Nanocomposite $450^{\circ} \mathrm{C}$ & $3.5 / 4.7$ \\
Nanocomposite $500^{\circ} \mathrm{C}$ & $4.0 / 4.8$ \\
AS $6000^{\circ} \mathrm{C}$ & $5.1-5.2$ \\
\hline
\end{tabular}

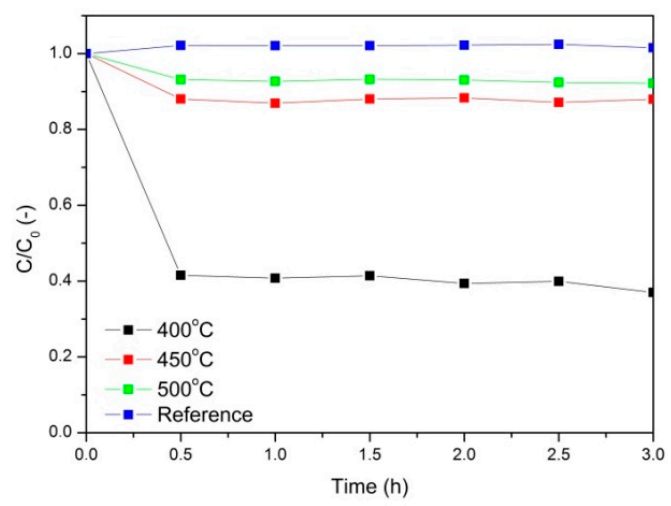

(a)

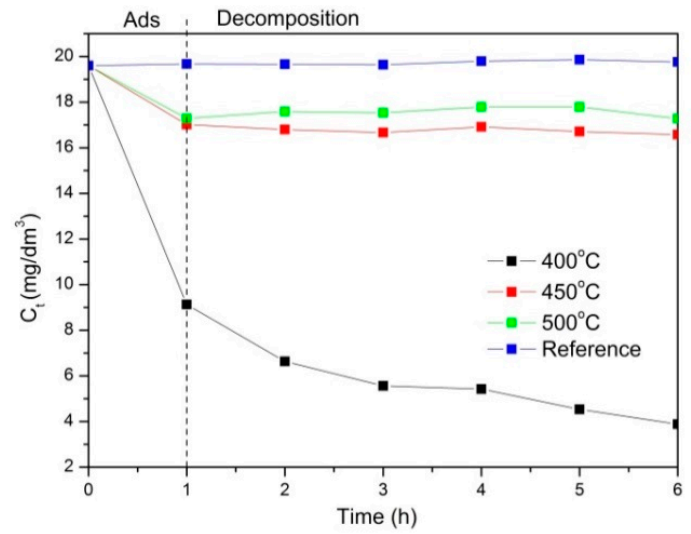

(b)

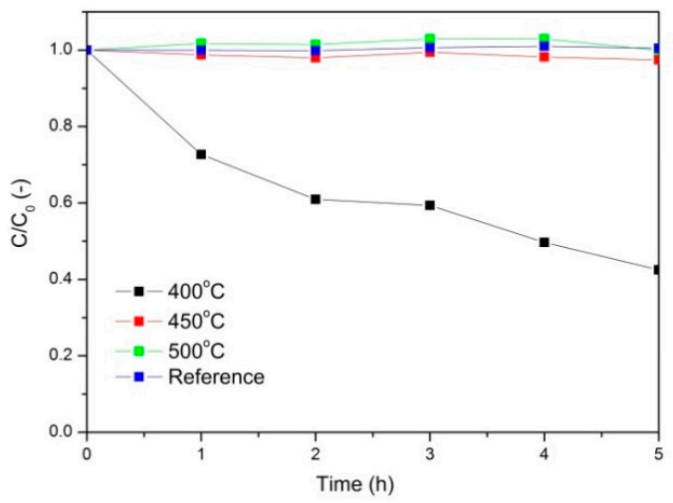

(c)

Figure 4. Adsorption of phenol (a) Photocatalytic decomposition of phenol, where (b) presents the absolute change of the phenol concentration and (c) presents the relative change of the phenol concentration. 


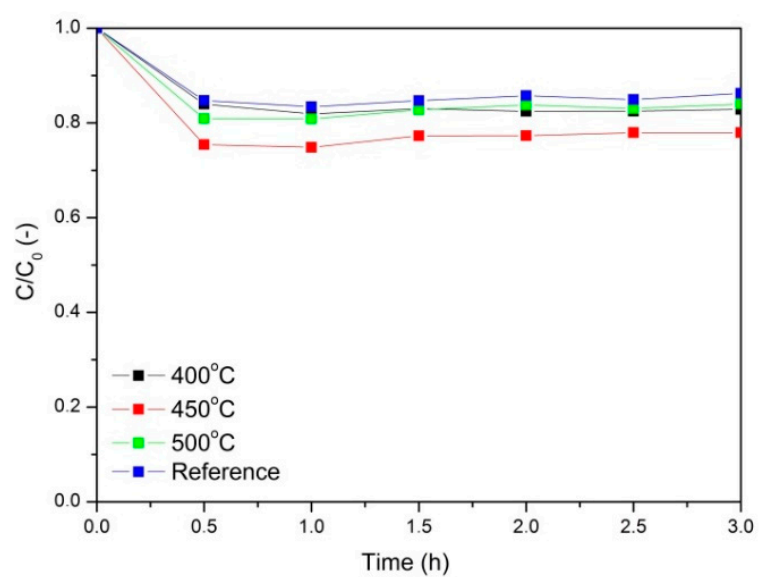

(a)

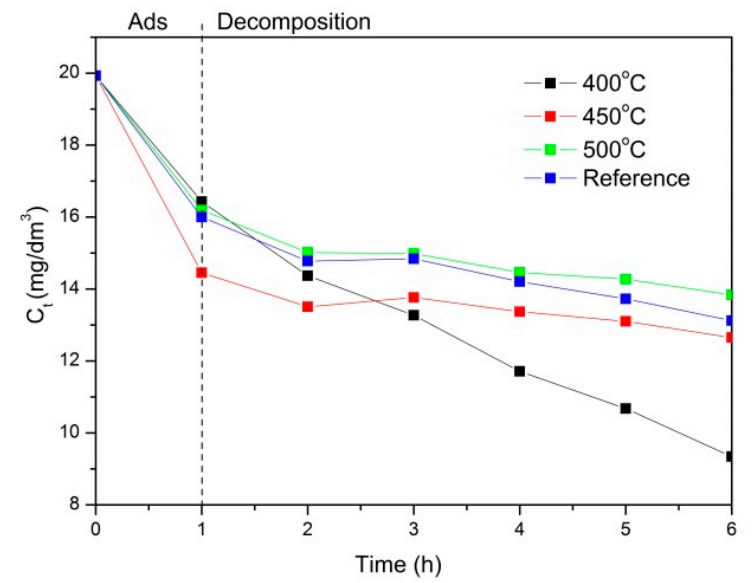

(b)

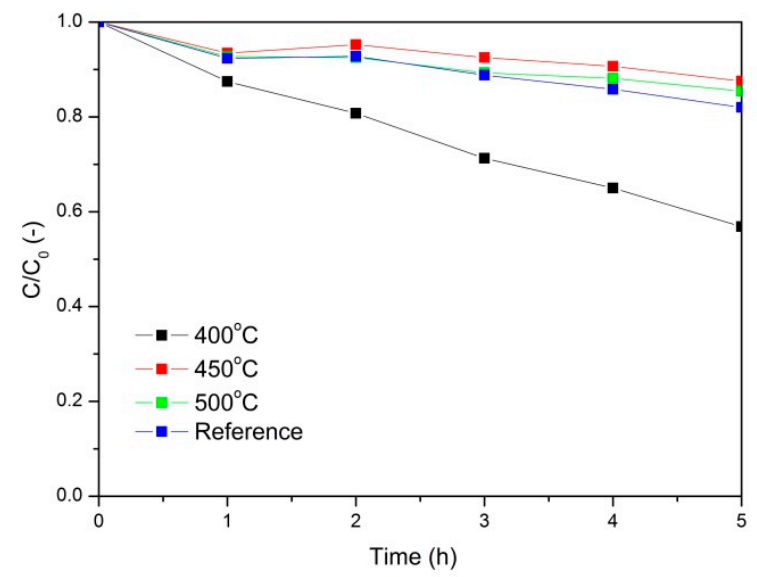

(c)

Figure 5. Adsorption of Orange II (a) Photocatalytic decomposition of Orange II, where (b) presents the absolute change of the phenol concentration and (c) presents the relative change of the phenol concentration.

Based on the analysis of the obtained results, it was found that for all the tested photocatalysts, the adsorption process took $1 \mathrm{~h}$ before the actual photocatalytic oxidation process took place. Figure $4 \mathrm{a}$, where the adsorption of phenol is presented, shows that the most efficient nanocomposite was the one annealed at $400{ }^{\circ} \mathrm{C}$. The aforementioned PCN nanocomposite adsorbed $60 \%$ of the phenol from the solution. The adsorption on the reference sample was negligible, and on the nanocomposites annealed at 450 and $500{ }^{\circ} \mathrm{C}$, approximately $10 \%$ of the phenol was adsorbed. 
Next, the solution was irradiated with UV light. The results of the phenol photocatalytic decomposition are shown in Figure $4 \mathrm{~b}$. In Figure $4 \mathrm{~b}$, the absolute change of the phenol concentration is shown. The first step of the process $(1 \mathrm{~h})$ occurred in the dark and corresponded to adsorption. After $1 \mathrm{~h}$, the UV light was turned on and the photocatalytic process was conducted. As a result, the most efficient material was the nanocomposite annealed at $400{ }^{\circ} \mathrm{C}$. There was no phenol decomposition on the reference material and very little phenol decomposition on the nanocomposites annealed at 450 and $500{ }^{\circ} \mathrm{C}$, which is also shown in Figure $4 \mathrm{c}$ in the change of the relative concentration of phenol. The final degree of phenol decomposition for the $\mathrm{PCN}$ nanocomposite annealed at $400{ }^{\circ} \mathrm{C}$ was approximately $58 \%$.

Another model pollutant used in the experiments was Orange II. The relative changes of the Orange II concentration during adsorption in the dark are presented in Figure 5a. The adsorption occurred the most efficiently on the nanocomposites annealed at $450{ }^{\circ} \mathrm{C}$, but it was only on the level of $25 \%$. For the other materials, the adsorption was less efficient.

In Figure $5 b$, the photocatalytic decomposition of Orange II is presented. After $1 \mathrm{~h}$ of adsorption in the dark, UV light was applied, and the decomposition of the pollutant started. At first, the decomposition was more efficient on the nanocomposites annealed at $450{ }^{\circ} \mathrm{C}$, but after $3 \mathrm{~h}$, the $\mathrm{PCN}$ nanocomposite annealed at $400{ }^{\circ} \mathrm{C}$ was the most effective, reaching (after $5 \mathrm{~h}$ ) $43 \%$ Orange II decomposition.

\section{Discussion}

The results show that the most promising material for photocatalytic applications is $\gamma-\mathrm{Al}_{2} \mathrm{O}_{3}-\mathrm{ZrO}_{2}$ covered by a PCN layer (Figure 6) obtained at $400{ }^{\circ} \mathrm{C}$. The temperature of $400^{\circ} \mathrm{C}$ is unexpected for PCN formation, because melamine, according to the literature [37], undergoes a transition to PCN above 600 ${ }^{\circ} \mathrm{C}$. In order to synthesize $\mathrm{PCN}$, the annealing of melamine has to be precisely stopped at the right time and at a given temperature. According to [37], the decomposition of melamine takes place through dimer (melam) and then trimer (melem) formation at a temperature below $400{ }^{\circ} \mathrm{C}$. Melem exists in the temperature range of $400-500{ }^{\circ} \mathrm{C}$. Above $600{ }^{\circ} \mathrm{C}$, melem starts to polymerize to PCN (melon) [37]. In our case, the formation of PCN took place at a $\sim 200{ }^{\circ} \mathrm{C}$ lower temperature than reported in the literature. In our opinion, this is due to the presence of nano-sized metal oxide in the nanocomposite and a fast heating rate $\left(50^{\circ} \mathrm{C} / \mathrm{min}\right)$. For comparison, the pure melamine decomposition temperature tested in our laboratory is the same as that reported in the literature [37], $\sim 600^{\circ} \mathrm{C}$. The presence of uniform, co-synthesized $\mathrm{AlOOH}-\mathrm{ZrO}_{2}$ nanopowder shifts the formation of $\mathrm{PCN}$ by $200{ }^{\circ} \mathrm{C}$ towards lower temperatures.

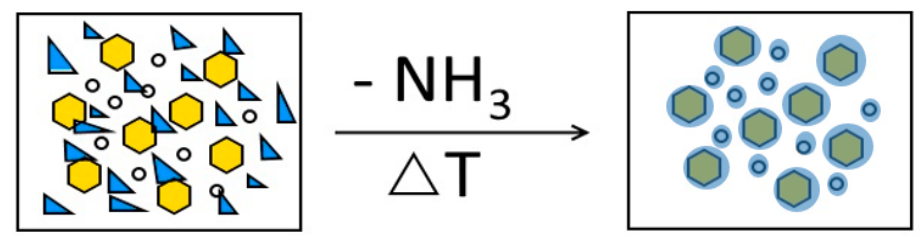

Figure 6. Scheme of $\mathrm{AlOOH}, \mathrm{ZrO}_{2}$, and melamine leading to the formation of the polymeric carbon nitride ( $\mathrm{PCN}$ ) nanocomposite. The circles represent $\mathrm{ZrO}_{2}$, the pentagons represent $\mathrm{AlOOH} / \mathrm{Al}_{2} \mathrm{O}_{3}$, and the blue triangles represent melamine powder.

The very fast heating $\left(50^{\circ} \mathrm{C} / \mathrm{min}\right)$ and long dwelling time at $400{ }^{\circ} \mathrm{C}(5 \mathrm{~h})$ applied in our synthesis process allows the covering of boehmite particles by an amorphous layer of $\mathrm{PCN}$ and allows $\mathrm{AlOOH}$ particles to transform into $\gamma-\mathrm{Al}_{2} \mathrm{O}_{3}$ without destroying the PCN layer (Figure 2d). We think that such phase transformation was possible without destroying the PCN layer, because it was a very slow process, which took place within the same crystal structure with cubic symmetry.

Covering $\gamma-\mathrm{Al}_{2} \mathrm{O}_{3}$ and $\mathrm{ZrO}_{2}$ nanoparticles with an amorphous layer of $\mathrm{PCN}$ in the nanocomposite annealed at $400^{\circ} \mathrm{C}$ can be also confirmed by the $\mathrm{SSA}_{\mathrm{BET}}$ results. Table 1 shows that the specific surface area of the $\mathrm{PCN}$ nanocomposite $\left(400{ }^{\circ} \mathrm{C}\right)$ is slightly lower than that of the $\gamma-\mathrm{Al}_{2} \mathrm{O}_{3}-\mathrm{ZrO}_{2}$ nanopowder 
but much smaller than the $\mathrm{SSA}_{\mathrm{BET}}$ of the nanocomposites prepared in the temperature range of $450-500{ }^{\circ} \mathrm{C}$. This can be explained by the covering of the surface of the nanoparticles with a thin organic layer and the fact that some PCN was formed in the gaps between particles.

Another confirmation of the PCN layer formation is the band gap value, $3 \mathrm{eV}$, which was significantly lower than the reference material (pure $\gamma-\mathrm{Al}_{2} \mathrm{O}_{3}-\mathrm{ZrO}_{2}$ nanopowders annealed at $600{ }^{\circ} \mathrm{C}$ ), characterized by 5.1 and $5.2 \mathrm{eV}$ band gaps. The layer presumably screens the nanoparticles from interaction with light, and they do not contribute to the overall band gap. On the other hand, pure PCN has a moderate bandgap of $2.7 \mathrm{eV}$, corresponding to an optical wavelength of $460 \mathrm{~nm}$ [14]. Considering the thermodynamic losses and other potentials in the photocatalytic process, the band gap of $2.7 \mathrm{eV}$ can be found in between $2 \mathrm{eV}$ and $3.1 \mathrm{eV}$ [14].

Polymeric carbon nitride materials have been investigated recently in various fields of photocatalysis $[1,3,6,7]$. Carbon nitrides have applications as sanitizers for the removal of contaminants, including pollutants and pathogenic microorganisms from drinking water and air [35]. There are also studies [1,26,38-41] in which PCN has been successfully used in the degradation of soluble dyes, such as methyl orange (MO), methylene blue (MB), phenol, rhodamine $\mathrm{B}$, and crystal violet (CV).

Vattikuti et al. [1] showed that $\mathrm{MoS}_{2} / \mathrm{Al}_{2} \mathrm{O}_{3} / \mathrm{g}-\mathrm{C}_{3} \mathrm{~N}_{4}$ nanocomposite has good photocatalytic performance for the degradation of $\mathrm{CV}$ dye under visible light irradiation. They reported [1] that the photodegradation rate of $\mathrm{CV}$ increased with the increasing $\mathrm{Al}_{2} \mathrm{O}_{3}$ and $\mathrm{MoS}_{2}$ content up to $20 \%$ in comparison with pure g- $\mathrm{C}_{3} \mathrm{~N}_{4}$. The photocatalytic activity of this nanocomposite was approximately 10.28 higher than that of pure g- $\mathrm{C}_{3} \mathrm{~N}_{4}$. On the other hand, He et al. [26] found that pure PCN was not as effective in phenol decomposition as a POMs-modified sample, where the concentration of phenol decreased up to $\sim 0.5$ over $3 \mathrm{~h}$. This result was worse than that in our case where the PCN nanocomposite annealed at $400{ }^{\circ} \mathrm{C}$ showed a decrease of phenol concentration to 0.5 over $30 \mathrm{~min}$ (Figure 4c). However, our outcomes are in contrast to the results described by Ren et al. [40], who investigated the photocatalytic properties of $\mathrm{Ag}_{2} \mathrm{O} / \mathrm{g}-\mathrm{C}_{3} \mathrm{~N}_{4}$ composites. They demonstrated high photocatalytic activity for phenol degradation [40]. They [40] showed that in $\mathrm{Ag}_{2} \mathrm{O} / \mathrm{g}-\mathrm{C}_{3} \mathrm{~N}_{4}$ composites under UV- and visible-light irradiation, phenol completely degraded in 20 and $90 \mathrm{~min}$, respectively. The improved photocatalytic activities were attributed to the formation of a heterostructure between $\mathrm{Ag}_{2} \mathrm{O}$ and $\mathrm{g}_{-} \mathrm{C}_{3} \mathrm{~N}_{4}$, the strong visible-light absorption, and the high separation efficiency of photoinduced electron-hole pairs resulting from the highly dispersed $\mathrm{Ag}_{2} \mathrm{O}$ particles [40].

In general, our findings regarding the photocatalytic activity of PCN nanocomposite are in agreement with others $[7,26,29,38,39,41]$. We think that photocatalytic efficiency depends more on the type of composite with PCN, then its specific surface area or porous volume structure. The photocatalytic properties of the PCN nanocomposites presented in this manuscript were investigated for the first time. Thus, it is difficult to compare our results with others. In summary, the addition of PCN nanocomposites to the presence of organic dyes and pollutants leads to relatively fast degradation of the contaminants.

\section{Materials and Methods}

The procedure for synthesizing nanopowders containing $\mathrm{AlOOH}$ with $\mathrm{ZrO}_{2}$ addition is described in detail elsewhere [23-25]. The reagents used in the process were zirconyl chloride octahydrate $\left(\mathrm{ZrOCl}_{2} \cdot 8 \mathrm{H}_{2} \mathrm{O}\right.$, Sigma-Aldrich, St. Louis, MI, USA $\left.(99.5 \%)\right)$, sodium hydroxide $(\mathrm{NaOH}$, analytically pure, Chempur, Piekary Sląskie, Poland), and aluminum nitrate nonahydrate $\left(\mathrm{Al}\left(\mathrm{NO}_{3}\right)_{3} \cdot 9 \mathrm{H}_{2} \mathrm{O}\right.$, analytically pure, Chempur, Piekary Slaskie, Poland). The microwave reactions took place in a microwave reactor $(2.45 \mathrm{GHz}, 600 \mathrm{~W}$, MAGNUM II ERTEC, Wrocław, Poland). As-prepared $\mathrm{AlOOH}-\mathrm{ZrO}_{2}$ nanopowder was hand mixed in a zirconia mortar with $20 \mathrm{wt} \%$ of melamine (Sigma-Aldrich, CAS Number 108-78-1 (99\%)). In the next step, the prepared powder was annealed in a tube furnace (homemade, Model 1, IHPP PAS, Warsaw, Poland) in 4 different temperatures (in 
the range of $400-600{ }^{\circ} \mathrm{C}$ ) for $5 \mathrm{~h}$ in air (Figure 7 ). In all cases, the constant heating rate of $50{ }^{\circ} \mathrm{C} / \mathrm{min}$ was applied.

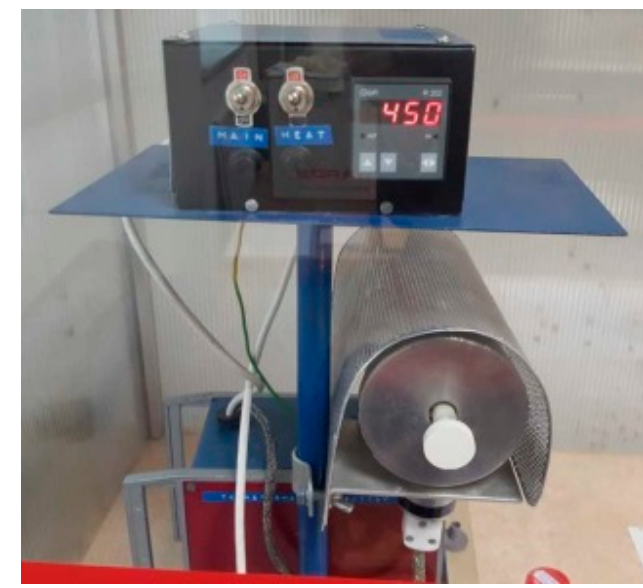

(a)

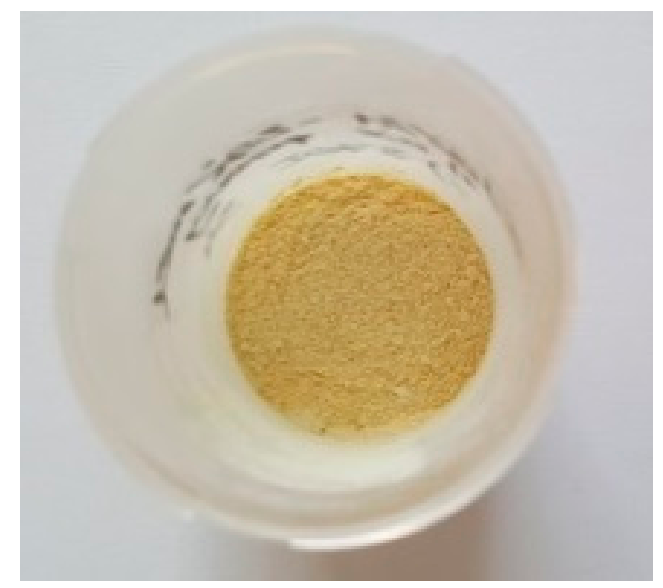

(b)

Figure 7. (a) Homemade tube furnace used for nanocomposites synthesis; (b) PCN nanocomposite obtained at $400{ }^{\circ} \mathrm{C}$.

All the powders after synthesis were exanimated using a Fourier transform infrared (FTIR) spectrometer (Bruker Optics, Tensor 27, Bruker BioSpin GmbH, Rheinstetten, Germany) equipped with a diamond attenuated total reflectance (ATR) accessory. The ATR-FTIR spectra were recorded at room temperature in the $4000-400 \mathrm{~cm}^{-1}$ range. The spectral resolution and accuracy of the measurements were $4 \mathrm{~cm}^{-1}$ and $1 \mathrm{~cm}^{-1}$, respectively.

X-ray diffraction (XRD) patterns of the nanopowders were collected on a diffractometer (X'Pert PRO, PANalytical, Almelo, Netherlands) equipped with a copper anode ( $\mathrm{Cu} K 1)$ and an ultra-fast PIXcel1D detector. The analysis was performed at room temperature in the $2 \theta$ range of $10-80^{\circ}$ with a step size of $0.03^{\circ}$.

The microstructures of the nanopowders and nanocomposites were investigated using conventional high-resolution (HR) transmission electron microscopy (TEM) and scanning (STEM) techniques with a FEI TECNAI G2 F20 S-TWIN electron microscope (Thermo Fisher Scientific, Waltham, MA, USA).

Helium density measurements were carried out using a helium pycnometer (AccuPyc II 1340, FoamPyc V1.06, Micromeritics, Norcross, GA, USA). The measurements were carried out in accordance with the ISO 12154:2014 standard at $25^{\circ} \mathrm{C}$.

The specific surface area of the nanopowders was determined using a surface analyzer (Gemini 262 2360, V 2.01, Micromeritics, Norcross, GA, USA). The nitrogen adsorption method was applied based on the linear 263 form of the Brunauer-Emmett-Teller (BET) isotherm equation. The obtained data were analyzed using the MicroActive software V4.03 (Interactive Data Analysis Software, Micromeritics). The detailed experimental procedure and the determination of particle size using the SSA $\mathrm{BET}_{\text {method }}$ is described elsewhere [42]. Based on the results of the specific surface area and density, the average particle size was calculated with the assumption that all the particles were spherical and identical.

The band gap experiments were conducted for nanocomposites formed into pellets. The UV-Vis reflectance of samples was measured at room temperature using Lambda 650 (Perkin-Elmer, Waltham, MA, USA) equipped with an integrating sphere module. Spectralon SRS-99-01030 reflectance material was used as a reference sample. The total reflectance of the samples was collected.

The photocatalytic activity of the obtained nanomaterials was determined on the basis of water pollutant degradation tests under the influence of UV-Vis radiation with high UV intensity (6 lamps, $20 \mathrm{~W}$ each, $40 \mathrm{~cm}$ long, type: ISOLDE, Koninklijke Philips N.V., Amsterdam, Netherlands). The lamp used in the experiments was not monochromatic. The wavelength range was from 200-800 nm. Phenol 
(neutral) and Orange II dye (anionic dye) were used as the model pollutants. In a $150 \mathrm{~cm}^{3}$ glass beaker, $20 \mathrm{mg}$ of the appropriate photocatalyst (nanocomposite) was suspended and then $100 \mathrm{~cm}^{3}$ of the dye or phenol solution with an initial concentration of $20 \mathrm{mg} / \mathrm{dm}^{3}$ was added. The final concentration of the catalyst in the mixture was $0,02 \mathrm{~g} / \mathrm{dm}^{3}$. The suspension was stirred continuously using a magnetic stirrer $(500 \mathrm{rpm})$. Further, suspensions were irradiated with ultraviolet light for $5 \mathrm{~h}$. The pollutant degradation process consisted of 2 stages. The first stage was an adsorption in a darkroom conducted until the equilibrium between the liquid and solid was established. The optimal time for adsorption was determined individually for each compound. Samples were taken at identical time intervals (every hour) and tested on a UV-Vis spectrophotometer. The concentrations of the individual samples were determined on the basis of calibration curve equations drafted for the given pollutants.

\section{Conclusions}

In this work a PCN- $\gamma-\mathrm{Al}_{2} \mathrm{O}_{3}-\mathrm{ZrO}_{2}$ nanocomposite was obtained for the first time.

The synthesis of the PCN-based nanocomposite photocatalyst consisted of two steps: (a) microwave hydrothermal synthesis of $\mathrm{AlOOH}-\mathrm{ZrO}_{2}$ nanopowders and (b) controlled addition of melamine to $\mathrm{AlOOH}-\mathrm{ZrO}_{2}$ nanopowders and subsequent thermal treatment to obtain $\mathrm{PCN}$-nanocomposites. This synthesis approach to $\mathrm{PCN}$-nanocomposites is unique and produces PCN nanocomposite photocatalysts, which are highly in demand, in an easy, clean, energy-efficient, and low-cost way.

It was shown that $\mathrm{PCN}$ was formed at the surface of $\gamma-\mathrm{Al}_{2} \mathrm{O}_{3}$ and $\mathrm{ZrO}_{2}$ at $400{ }^{\circ} \mathrm{C}$ by means of a melamine thermal condensation process, which took place at a $\sim 200^{\circ} \mathrm{C}$ lower temperature than the state of the art. We postulate that this was possibly due to the interaction of the melamine with the $\gamma-\mathrm{Al}_{2} \mathrm{O}_{3}$ and $\mathrm{ZrO}_{2}$ nanoparticles, which provide high specific surface areas and morphology favorable for the formation of a PCN layer.

It was observed that $\mathrm{AlOOH}$ fully transformed into $\gamma-\mathrm{Al}_{2} \mathrm{O}_{3}$ without affecting the $\mathrm{PCN}$ layer structure.

The PCN nanocomposite has a $3 \mathrm{eV}$ band gap and shows significant photocatalytic ability for common pollutant adsorption and degradation. The proposed simple and low-cost preparation method permits the exploitation of PCN as a polymer semiconductor photocatalytic material.

Author Contributions: Conceptualization, I.K.; Funding acquisition, I.K. and W.L.; Investigation, I.K., J.W., P.N., J.S.-K., S.S., A.B., A.M., and W.L.; Methodology, I.K.; Supervision, I.K.; and Original draft preparation, I.K. This publication is part of I.K.'s habilitation thesis.

Funding: This research was funded by the Polish National Science Centre grant number: UMO-2013/11/D/ST8/03429- "Sonata 6". The research subject was partly carried out with the use of equipment funded by the project CePT, reference: POIG.02.02.00-14-024/08, financed by the European Regional Development Fund within the Operational Programme "Innovative Economy" for 2007-2013.

Acknowledgments: The authors are indebted to Jan Mizeracki for help with the materials' preparation.

Conflicts of Interest: The authors declare no conflicts of interest.

\section{References}

1. Vattikuti, S.V.P.; Byon, C. Hydrothermally synthesized ternary heterostructured $\mathrm{MoS}_{2} / \mathrm{Al}_{2} \mathrm{O}_{3} / \mathrm{g}-\mathrm{C} 3 \mathrm{~N} 4$ photocatalyst. Mater. Res. Bull. 2017, 96, 233-245. [CrossRef]

2. Chen, J.; Garcia, E.D.; Oliviero, E.; Oliviero, L.; Maugé, F. Effect of high pressure sulfidation on the morphology and reactivity of $\mathrm{MoS}_{2}$ slabs on $\mathrm{MoS}_{2} / \mathrm{Al}_{2} \mathrm{O}_{3}$ catalyst prepared with citric acid. J. Catal. 2016, 339, 153-162. [CrossRef]

3. Reddy, P.A.K.; Reddy, P.V.L.; Kwon, E.; Kim, K.; Akter, T.; Kalagara, S. Recent advances in photocatalytic treatment of pollutants in aqueous media. Environ. Int. 2016, 91, 94-103. [CrossRef] [PubMed]

4. Li, H.; Yin, S.; Wang, Y.; Sekino, T.; Lee, S.W.; Sato, T. Roles of Cr3+ doping and oxygen vacancies in $\mathrm{SrTiO}_{3}$ photocatalysts with high visible light activity for NO removal. J. Catal. 2013, 297, 65-69. [CrossRef] 
5. Aman, N.; Das, N.N.; Mishra, T. Effect of N-doping on visible light activity of $\mathrm{TiO}_{2}-\mathrm{SiO}_{2}$ mixed oxide photocatalysts. J. Environ. Chem. Eng. 2016, 4, 191-196. [CrossRef]

6. Yu, W.; Zhang, J.; Peng, T. New insight into the enhanced photocatalytic activity of N-, C-and S-doped ZnO photocatalysts. Appl. Catal. B Environ. 2016, 181, 220-227. [CrossRef]

7. Ge, L.; Han, C.; Xiao, X.; Guo, L.; Li, Y. Enhanced visible light photocatalytic hydrogen evolution of sulfur-doped polymeric g-C3N4 photocatalysts. Mater. Res. Bull. 2013, 48, 3919-3925. [CrossRef]

8. Song, Y.; Wei, S.; Rong, Y.; Lu, C.; Chen, Y.; Wang, J.; Zhang, Z. Enhanced visible light photocatalytic hydrogen evolution activity of $\mathrm{Er} 3+: \mathrm{Y}_{3} \mathrm{Al}_{5} \mathrm{O}_{12} / \mathrm{PdSeZnS}$ by conduction band co-catalysts $\left(\mathrm{MoO}_{2}, \mathrm{MoS}_{2}\right.$ and $\mathrm{MoSe}_{2}$ ). Int. J. Hydrogen Energy 2016, 41, 12826-12835. [CrossRef]

9. Jin, C.; Liu, G.; Zu, L.; Qin, Y.; Yang, J. Preparation of $\mathrm{Ag} @ \mathrm{Ag}_{3} \mathrm{PO}_{4} @ \mathrm{ZnO}$ ternary heterostructures for photocatalytic studies. J. Colloid Interface Sci. 2015, 453, 36-41. [CrossRef] [PubMed]

10. Wang, X.; Maeda, K.; Thomas, A.; Takanabe, K.; Xin, G.; Carlsson, J.M.; Domen, K.; Antonietti, M. A metal-free polymeric photocatalyst for hydrogen production from water under visible light. Nat. Mater. 2009, 8, 76-80. [CrossRef] [PubMed]

11. Kessler, F.K.; Zheng, Y.; Schwarz, D.; Merschjann, C.; Schnick, W.; Wang, X.; Bojdys, M.J. Functional carbon nitride materials design strategies for electrochemical Devices. Nat. Rev. Mater. 2017, 2, 1-17. [CrossRef]

12. Duan, J.; Chen, S.; Jaroniec, M.; Qiao, S. Porous C3N4 nanolayers@N-graphene films as catalyst electrodes for highly efficient hydrogen evolution. ACS Nano 2015, 9, 931-940. [CrossRef] [PubMed]

13. Ye, S.; Wang, R.; Wu, M.Z.; Yuan, Y.P. A review on g-C3N4 for photocatalytic water splitting and $\mathrm{CO}_{2}$ reduction. Appl. Surf. Sci. 2015, 358, 15-27. [CrossRef]

14. Wen, J.; Xie, J.; Chen, X.; Li, X. A review on g-C3N4-based photocatalysts. Appl. Surf. Sci. 2017, 391, 72-123. [CrossRef]

15. Ma, T.; Dai, S.; Jaroniec, M.; Qiao, S. Graphitic carbon nitride nanosheet-carbon nanotube three-dimensional porous composites as high-performance oxygen evolution electrocatalysts. Angew. Chem. Int. Ed. 2014, 53, 7281-7285. [CrossRef] [PubMed]

16. Wang, X.; Liu, C.; Li, X.-L.; Li, F.-T.; Li, Y.-P.; Zhao, J.; Liu, R.-H. Construction of g-C3N4/ $\mathrm{Al}_{2} \mathrm{O}_{3}$ hybrids via in-situ acidification and exfoliation with enhanced photocatalytic activity. Appl. Surf. Sci. 2017, 394, 340-350. [CrossRef]

17. Feng, D.; Cheng, Y.; He, J.; Zheng, L.; Shao, D.; Wang, W.; Wang, W.; Lu, F.; Dong, H.; Liu, H.; et al. Enhanced photocatalytic activities of g-C3N4 with large specific surface area via a facile one-step synthesis process. Carbon 2017, 125, 454-463. [CrossRef]

18. Li, S.; Wang, Z.; Wang, X.; Sun, F.; Gao, K.; Hao, N. Orientation controlled preparation of nanoporous carbon nitride fibers and related composite for gas sensing under ambient conditions. Nano Res 2017, 10, 1710-1719. [CrossRef]

19. Sun, J.; Zhang, J.; Zhang, M.; Antonietti, M.; Fu, X.; Wang, X. Bioinspired hollow semiconductor nanospheres as photosynthetic nanoparticles. Nat. Commun. 2012, 3, 1139-1145. [CrossRef]

20. Li, X.; Zhang, J.; Chen, X.; Fischer, A.; Thomas, A.; Antonietti, M. Condensed graphitic carbon nitride nanorods by nanoconfinement: Promotion of crystallinity on photocatalytic conversion. Chem. Mater. 2011, 23, 4344-4348. [CrossRef]

21. Li, X.; Wang, X.; Antonietti, M. Mesoporous g-C3N4 nanorods as multifunctional supports of ultrafine metal nanoparticles: Hydrogen generation from water and reduction of nitrophenol with tandem catalysis in one step. Chem. Sci. 2012, 3, 2170-2174. [CrossRef]

22. Hu, M.; Reboul, J.; Furukawa, S.; Radhakrishnan, L.; Zhang, Y.; Srinivasu, P.; Iwai, H.; Wang, H.; Nemoto, Y.; Suzuki, N.; et al. Direct synthesis of nanoporous carbon nitride fibers using Al-based porous coordination polymers (Al-PCPs). Chem. Commun. 2011, 47, 8124-8126. [CrossRef] [PubMed]

23. Koltsov, I.; Smalc-Koziorowska, J.; Przesniak-Welenc, M.; Małysa, M.; Kimmel, G.; McGlynn, J.; Ganin, A.; Stelmakh, S. Mechanism of Reduced Sintering Temperature of $\mathrm{Al}_{2} \mathrm{O}_{3}-\mathrm{ZrO}_{2}$ Nanocomposites Obtained by Microwave Hydrothermal Synthesis. Materials 2018, 11, 829. [CrossRef] [PubMed]

24. Malka, I.E.; Danelska, A.; Kimmel, G. The Influence of $\mathrm{Al}_{2} \mathrm{O}_{3}$ Content on $\mathrm{ZrO}_{2}-\mathrm{Al}_{2} \mathrm{O}_{3}$ Nanocomposite Formation-The Comparison between Sol-Gel and Microwave Hydrothermal Methods. Mater. Today Proc. 2016, 3, 2713-2724. [CrossRef] 
25. Koltsov, I.; Przesniak-Welenc, M.; Wojnarowicz, J.; Rogowska, A.; Mizeracki, J.; Malysa, M.; Kimmel, G. Thermal and physical properties of $\mathrm{ZrO}_{2}-\mathrm{AlO}(\mathrm{OH})$ nanopowders synthesised by microwave hydrothermal method. J. Therm. Anal. Calorim. 2017, 131, 2273-2284. [CrossRef]

26. He, J.; Sun, H.; Indrawirawan, S.; Duan, X.; Tade, M.O.; Wang, S. Novel polyoxometalate@g-C3N4 hybrid photocatalysts for degradation of dyes and phenolics. J. Coloid Interf. Sci. 2015, 456, 15-21. [CrossRef] [PubMed]

27. Opalinska, A.; Malka, I.; Dzwolak, W.; Chudoba, T.; Presz, A.; Lojkowski, W. Size-dependent density of zirconia nanoparticles. Beilstein J. Nanotechnol. 2015, 6, 27-35. [CrossRef] [PubMed]

28. Wojnarowicz, J.; Chudoba, T.; Koltsov, I.; Gierlotka, S.; Dworakowska, S.; Lojkowski, W. Size control mechanism of $\mathrm{ZnO}$ nanoparticles obtained inmicrowave solvothermal synthesis. Nanotechnology 2018, 29, 065601. [CrossRef] [PubMed]

29. Sano, T.; Tsutsui, S.; Koike, K.; Hirakawa, T.; Teramoto, Y.; Negishi, N.; Takeuchi, K. Activation of graphitic carbon nitride (g-C3N4) by alkaline hydrothermal treatment for photocatalytic NO oxidation in gas phase. J. Mater. Chem. A 2013, 1, 6489. [CrossRef]

30. Nowak, M.; Kauch, B.; Szperlich, P. Determination of energy band gap of nanocrystalline SbSI using diffuse reflectance spectroscopy. Rev. Sci. Instrum. 2009, 80, 046107. [CrossRef] [PubMed]

31. Köferstein, R.; Jäger, L.; Ebbinghaus, S.G. Magnetic and optical investigations on $\mathrm{LaFeO}_{3}$ powders with different particle sizes and corresponding ceramics. Solid State Ionics 2013, 249-250, 1-5. [CrossRef]

32. Kubelka, P.; Munk, F. Ein Beitrag zur Optik der Farbanstriche. Zeitschrift für Technische Physik 1931, 12, 593-601.

33. Philips-Invernizzi, B.; Dupont, D.; Caze, C. Bibliographical review for reflectance of diffusing media. Opt. Eng. 2001, 40, 1082-1093. [CrossRef]

34. Tauc, J.; Grigorovici, R.; Vancu, A. Optical Properties and Electronic Structure of Amorphous Germanium. Phys. Status Solidi B 1966, 15, 627-637. [CrossRef]

35. Davis, E.A.; Mott, N.F. Conduction in non-crystalline systems V. Conductivity, optical absorption and photoconductivity in amorphous semiconductors. Philos. Mag. 1970, 22, 0903-0922. [CrossRef]

36. Kortüm, G.; Vogel, J. Die Theorie der diffusen Reflexion von Licht an pulverförmigen Stoffen. Z. Phys. Chem. 1958, 18, 110-122. [CrossRef]

37. Praus, P.; Svoboda, L.; Ritz, M.; Troppová, I.; Šihor, M.; Kočía, K. Graphitic carbon nitride: Synthesis, characterization and photocatalytic decomposition of nitrous oxide. Mater. Chem. Phys. 2017, 193, 438-446. [CrossRef]

38. Cui, Y.; Ding, Z.; Liu, P.; Antonietti, M.; Fu, X.; Wang, X. Metal-free activation of $\mathrm{H}_{2} \mathrm{O}_{2}$ by g-C3N4 under visible light irradiation for the degradation of organic pollutants. Phys. Chem. Chem. Phys. 2012, 14, 1455-1462. [CrossRef] [PubMed]

39. Zhang, M.; Jiang, W.; Liu, D.; Wang, J.; Liu, Y.; Zhu, Y.; Zhu, Y. Photodegradation of phenol via C3N4-agar hybrid hydrogel 3Dphotocatalysts with free separation. Appl. Catal. B Environm. 2016, 183, 263-268. [CrossRef]

40. Ren, H.-T.; Jia, S.-Y.; Wu, Y.; Wu, S.-H.; Zhang, T.-H.; Han, X. Improved Photochemical Reactivities of $\mathrm{Ag}_{2} \mathrm{O} / \mathrm{g}-\mathrm{C} 3 \mathrm{~N} 4$ in Phenol Degradation under UV and Visible Light. Ind. Eng. Chem. Res. 2014, 53, 17645-17653. [CrossRef]

41. Shi, L.; Zhao, K.; Liu, S. Photocatalytic degradation of MO and phenol over novel $\beta-\mathrm{CoOOH} / \mathrm{g}-\mathrm{C} 3 \mathrm{~N} 4$ composite under visible light irradiation. Mater. Lett. 2018, 228, 121-124. [CrossRef]

42. Wojnarowicz, J.; Opalinska, A.; Chudoba, T.; Gierlotka, S.; Mukhovskyi, R.; Pietrzykowska, E.; Sobczak, K.; Lojkowski, W. Effect of water content in ethylene glycol solvent on the size of ZnO nanoparticles prepared using microwave solvothermal synthesis. J. Nanomater. 2016, 2016, 2789871. [CrossRef]

Sample Availability: Samples of the all compounds described in this work are available from I.K. 